Boise State University

ScholarWorks

Public Policy and Administration Faculty

Publications and Presentations

Department of Public Policy and Administration

$1-1-2016$

Reflections on Recent Recommendations on the Use of Science in Disaster Risk Reduction Using Case Studies from Bangladesh and the Western United States

Susanne Sargeant

British Geological Survey

Eric Lindquist

Boise State University

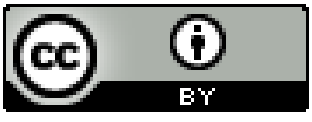

This document was originally published in GSA Special Papers by the Geological Society of America. This work is provided under a Creative Commons Attribution license. Details regarding the use of this work can be found at: http://creativecommons.org/licenses/by/4.0/.doi: 10.1130/

2016.2520(27) 


\title{
Reflections on recent recommendations on the use of science in disaster risk reduction using case studies from Bangladesh and the western United States
}

\author{
Susanne Sargeant* \\ British Geological Survey, Edinburgh EH14 4AP, UK \\ Eric Lindquist* \\ Public Policy Research Center, Boise State University, Boise, Idaho 83725, USA
}

\begin{abstract}
The valuable role that science has to play in disaster preparedness and risk reduction is widely recognized and was highlighted during the development of the successor to the Hyogo Framework for Action for disaster risk reduction that was adopted in March 2015. However, there are many factors that limit how effectively science can inform both disaster risk reduction policy and practice. Understanding these factors and taking steps to overcome them require a broad view, and a comparative approach can be instructive. We focus on two projects that were independently completed by the authors: earthquake risk management in Bangladesh and flooding and wildfires management in the United States. We use each case to reflect on the implications of recent recommendations made by the Science and Technology Advisory Group (STAG) of the United Nations Office for Disaster Risk Reduction that attempt to increase the integration of science in disaster risk reduction policy making. We then use the STAG recommendations as a framework for integrating our independent case study findings. Despite the differences in the geographic contexts and hazards being considered, these examples broadly support the STAG recommendations. However, the fine details of the way in which science is used in decision making need to be given careful consideration if science is to fully support disaster risk reduction. Although our collective observations suggest that science is an important part of the disaster risk reduction (DRR) process, suggesting that it is "key to post-2015 DRR efforts" as the STAG recommendations do, may perhaps overstate the role that science is able to play.
\end{abstract}

*slsa@bgs.ac.uk; ericlindquist@boisestate.edu

Gold Open Access: This chapter is published under the terms of the CC-BY license and is available open access on www.gsapubs.org.

Sargeant, S., and Lindquist, E., 2016, Reflections on recent recommendations on the use of science in disaster risk reduction using case studies from Bangladesh and the western United States, in Wessel, G.R., and Greenberg, J.K., eds., Geoscience for the Public Good and Global Development: Toward a Sustainable Future: Geological Society of America Special Paper 520, p. 311-320, doi:10.1130/2016.2520(27). For permission to copy, contact editing @ geosociety.org. (C 2016 Susanne Sargeant and Eric Lindquist. All rights reserved. 


\section{INTRODUCTION}

The role for science and scientists in disaster risk reduction has been well established in that progress toward reducing risk and increasing resilience requires accessible, easy-to-understand scientific information that can be integrated with other types of knowledge (e.g., local knowledge) for decision and policy making (Basher, 2013; Carter et al., 2014; Southgate et al., 2013). It is important to understand how science is integrated into disaster risk reduction in practice because the process is often complex (Gaillard and Mercer, 2012) and may not follow the linear communication model that is frequently assumed (see, for example, Javeline and Shufeldt, 2014; Turnhout et al., 2013). One approach is to use and compare case studies, and here we present examples from Bangladesh (earthquakes) and the western United States (flooding and wildfires).

The point of convergence for the case studies discussed here is global disaster risk reduction policy. At the time of writing (October 2014), the Hyogo Framework for Action (HFA) 20052015 (UNISDR, 2005) was being implemented. The HFA set out the work required from all pertinent sectors and stakeholders to reduce disaster losses. The anticipated role of science and scientists was indicated within the priorities for action of the HFA-in priority 2 (risk assessment, loss estimation, space-based observation, early warning and forecasting), more generally in priority 3 (the importance of information sharing and cooperation, and cross-disciplinary networks), and in priority 5 (developing technical and institutional capacity for effective disaster management).

In March 2015, the framework for disaster risk reduction beyond 2015 was adopted at the Third United Nations (UN) World Conference on Disaster Risk Reduction in Sendai, Japan, but at the time of writing, the zero draft of the post-2015 framework had just been released by the UN. This draft was shaped by the views of the UN member states, major civil society groups (including science and technology stakeholders), the six regional platforms for disaster risk reduction (multiple-stakeholder forums that bring together groups including governments, UN organizations, nongovernmental organizations [NGOs], and the private sector), ministerial meetings, and reports from other multiple-stakeholder consultations. It specifically calls for support for the interface between policy and science for effective decision making.

During the lengthy international consultation process for the post-2015 framework, one of the most pointed and prescriptive approaches to articulating the role that science must play was presented in the report of the United Nations Office for Disaster Risk Reduction (UNISDR) Scientific and Technical Advisory Group (STAG; Southgate et al., 2013; see also Carter et al., 2014). The purpose of the STAG is to provide technical advice and support in the formulation and implementation of disaster risk reduction activities. It aims to encompass all aspects of the scientific and technical dimensions of risk reduction. In Southgate et al. (2013, p. 7), the STAG highlights the need for "more effective interplay of science, policy and practice in support of disaster risk reduc- tion" and for research agendas to be developed in cooperation with stakeholders to ensure that scientists' work is focused on developing solutions. They also state that interaction and communication between the science community and policy makers should be better and faster. In addition, the STAG makes the following recommendations:

Recommendation 1: "Encourage science to demonstrate that it can inform policy and practice" (Southgate et al., 2013, p. 7), particularly through the use of case studies that show that science is able to identify a problem, understand that problem through research, inform policy and practice, and make a measurable difference.

Recommendation 2: "Use a problem-solving approach to research that integrates all hazards and disciplines" (Southgate et al., 2013, p. 7). The recommendation highlights the importance of collaboration and communication across scientific disciplines and with all stakeholders in order to capture the complexity of disaster risk and develop improved and more effective solutions.

Recommendation 3: "Promote knowledge into action" (Southgate et al., 2013, p. 8), with greater emphasis on sharing and dissemination of information and ensuring that science can be integrated into policies, regulations, and implementation.

Recommendation 4: "Science should be key to the post-2015 HFA." Southgate et al. (2013, p. 8) call on scientists to provide evidence of the impact that science is able to have on tackling disaster risk.

Here, we take a multidisciplinary approach and use two case studies to explore the implications of these recommendations. We characterize our approach as multidisciplinary, in contrast to interdisciplinary, as the cases were developed independently and then integrated. The first case is an earthquake risk management training course for staff in the humanitarian and development sector in Bangladesh that was developed by Sargeant. The second case study is on the efforts under way to manage the risk of flooding and wildfires in the Boise River Basin of southwest Idaho in the western United States, in which Lindquist has participated. The way that the two cases are presented reflects our disciplinary backgrounds, perspectives, and positions in the process. While these seemingly disparate cases were initiated independently, together they present an opportunity to explore the recommendations of the Southgate et al. (2013) report from a comparative perspective. This provides deeper insight into the way in which science is used in disaster risk reduction than a single case study would afford. The comparative perspective also addresses recognized concerns and gaps in disaster risk reduction decisionmaking knowledge and action and sets the stage for future, more systematic assessments of interest to the geoscience, social science, and practitioner communities (UNISDR, 2009).

In the following sections, we first outline the context for each case study and the way in which science has informed the disaster risk reduction process. We then reflect on the implications of the STAG recommendations for each of the case studies separately. Next, we integrate our findings, again taking the STAG recommendations as our framework for this, and we consider the similarities and differences between the two cases. In doing so, 
not only do we compare between hazards and geographic contexts, but also between disciplines (physical science, and social and political science). In the conclusion, we reflect on the utility and limitations of our multidisciplinary approach, and we propose some paths forward to address the overarching question of how science can be used for disaster risk reduction.

\section{CASE STUDIES ON THE USE OF SCIENCE IN DISASTER RISK REDUCTION}

Working independently, we have been involved in disaster risk reduction-related activities for different natural hazards in two very different regions: earthquakes in Bangladesh, and wildfires and floods in the semiarid region of southwest Idaho, in the western United States. This section details the two cases and articulates the diverse perspectives that the respective disciplinary backgrounds of each author brought to the research. The integration of the cases and implications for the STAG recommendations in Southgate et al. (2013) are addressed in the next section.

\section{Earthquakes in Bangladesh}

Bangladesh is one of the most densely populated countries in the world. It has recorded annual gross domestic product (GDP) growth of around $6 \%$ since 2008, but frequent natural disasters pose significant development challenges (e.g., World Bank, 2010). Water exerts an enormous influence on human life in Bangladesh through rainfall, river inundation, flash floods, storm surges, and droughts (e.g., Van Schendel, 2010), and human losses due to cyclones have been very high. Bangladesh is also a seismically active region and has a history of large damaging earthquakes (Fig. 1). Particularly notable earthquakes occurred in A.D. 1762 and 1897. The A.D. 1762 Arakan earthquake occurred off the east coast of Bangladesh, which Wang et al. (2013) estimated had a magnitude of $\sim 8.5 \mathrm{Mw}$ (moment magnitude). This event caused widespread heavy damage, liquefaction and landslides in the Chittagong region, and a rapid increase in the level of the river at Dhaka that drove hundreds of boats onshore and caused significant loss of life (Martin and Szeliga, 2010). The Great Assam earthquake of A.D. 1897 ( $\mathrm{Mw}>$ 8) destroyed all masonry buildings over a large part of northeastern India and caused heavy damage in Dhaka (Bilham and England, 2001; Martin and Szeliga, 2010). There have been no earthquakes greater than around magnitude 7 in the Bangladesh region since 1930, despite their relatively frequent occurrence in the eighteenth, nineteenth, and early twentieth centuries (A.D. 1762, 1842, 1865, 1868, 1897, 1918, 1923, and 1930). Since that time, the population of Bangladesh has risen to $\sim 156$ million in 2013 (World Bank, 2013), and the metropolitan areas of the main cities of Dhaka and Chittagong now have populations of $\sim 16$ million and 7 million, respectively. In general, urban areas in Bangladesh are expanding rapidly, and many new buildings are under construction. There is significant competition for space, and enforcement of an adequate building code is lacking (UNISDR, 2013). As a result, building vulnerabil- ity is high, and building collapses, simply because of poor construction practices, are not uncommon, e.g., the collapse of the Rana Plaza in April 2013, in which over 1000 people were killed.

Since November 2012, the Bangladesh Department of Disaster Management (DDM), under the Ministry of Disaster Management and Relief, has had the mandate to implement the objectives of the Disaster Management Act. The DDM implements the objectives through a wide range of activities, including risk reduction activities (e.g., the Comprehensive Disaster Management Programme [CDMP], a collaborative initiative of the Bangladesh government and United Nations Development Programme), enhancing capacity of poor and disadvantaged people, and strengthening and coordinating programs being undertaken by government and NGOs that relate to disaster risk reduction and emergency response.

Foreign aid and investment have played a key role in Bangladesh's evolution, and there is a large NGO presence in the country. NGOs are seen as being an important group for implementing disaster risk reduction initiatives because they work at a grassroots level using participatory methodologies, often working with the most vulnerable people in society (e.g., UNISDR, 2006). In Bangladesh, the National Alliance for Risk Reduction and Response Initiatives (NARRI) consortium of international humanitarian and development NGOs is an important group engaged in disaster risk reduction.

From a review of $30 \mathrm{yr}$ of humanitarian response to earthquakes, Cosgrave (2008) presents a list of possible earthquake risk reduction activities that these kinds of organizations might undertake. These activities include raising awareness of risk assessment and mitigation measures at a community level, training communities in first aid and search and rescue, helping at-risk communities develop disaster, evacuation, and community contingency action plans, integrating risk management in long-term planning, providing opportunities for community members to participate in the urban planning process, protecting key infrastructure such as hospitals, and working with communities to identify risks and promote safe siting of buildings.

Scientific knowledge and information clearly must support these undertakings. However, ensuring that these activities and other operational decisions are based on scientific understanding of the earthquake threat can present challenges for this sector, such as identifying and accessing credible, reliable, trustworthy, and usable information. Anecdotal evidence indicates that some NGOs operating in Haiti before the devastating 2010 earthquake were not aware of the potential for a large earthquake hitting Portau-Prince, despite this being well established in the scientific literature. A key issue is therefore to ensure that NGOs engaged in disaster risk reduction activities are aware of and have access to appropriate scientific knowledge and expertise, and also understand its implications, which can then inform both their programming and organizational activities.

The aim of this project was to increase the use of earthquake information in NGO operations in Bangladesh through a knowledge-exchange project funded by the Natural Environment 


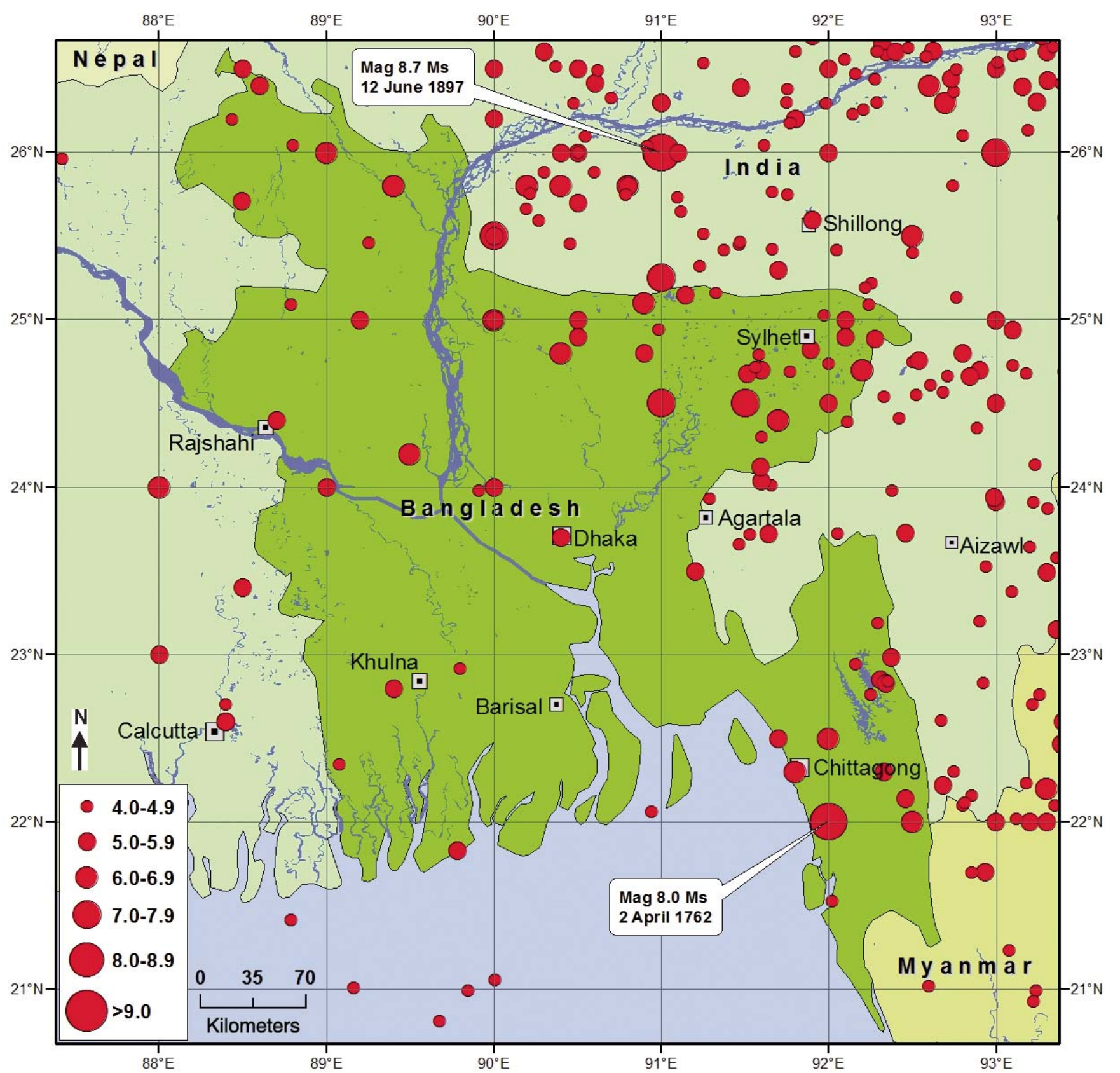

Figure 1. Seismicity of the Bangladesh region taken from the British Geological Survey World Seismicity Database (Henni et al., 1998).

Research Council in the UK. The project brought together a seismologist (Sargeant), staff from Concern Worldwide (an international NGO working in Bangladesh), and the International Rescue Corps (IRC). The IRC is an urban search-and-rescue charity based in the UK with significant experience of responding to international disasters, including major earthquakes. Following initial activities (starting in 2010) in order to understand the local disaster risk reduction context in Bangladesh and the way in which these types of organizations absorb and act on information (e.g., meetings between Sargeant and staff members from Con- cern Bangladesh, representatives of the CDMP, and other disaster risk reduction stakeholders), the group worked together to develop a training course that would support NGO staff to make use of existing scientific information and focus on the implications for operational decision making.

In November 2012, a three day earthquake risk management training course was held in Dhaka for 18 staff working for seven NGOs, including Concern Worldwide and other members of the NARRI consortium. The course was facilitated by the scientist (Sargeant) and the Operational Director from IRC, 
although there was a focus on everyone learning together from the very beginning given the diversity of skills, experience, and knowledge amongst the 20 people present. A mixture of relatively informal lectures, focus groups, and practical exercises was used. Increasing general knowledge of earthquakes and the hazard in Bangladesh was a crucial part of the training because the level of awareness amongst the attendees was relatively low. Introductions to seismic hazard and risk assessment were part of the course, complemented by presentations made by some of the attendees on the community risk assessment process used by NGOs and the earthquake scenarios developed for Dhaka, Chittagong, and Sylhet for the CDMP in Bangladesh.

The aim of the lectures was to raise awareness of the different sources of knowledge and information, and of the different working practices amongst the group to inform the focus group discussions that took place in the afternoons. The group discussions were guided by a series of questions designed to explore how different operational aspects might be affected by an earthquake, what would be needed to make these aspects less vulnerable, and what information and action would be required to do this. The potential impacts of an earthquake on their projects and beneficiaries in rural and urban areas were considered, as well as on current projects in sectors such as livelihood security, and health and education, and operational aspects such as logistics, facilities and information technology, and administration, human resources, and finance. Some of the focus group outputs are shown in Figure 2. In all the discussions, science soon became just one of many facets of the conversation.

The participatory style of the course (numerous focus group discussions alongside the more formal lectures) had several potential advantages. First, it echoed the approach that these organizations use when working with their staff and their beneficiaries and so was familiar to the participants. Second, it allowed for discussion of the implications of the scientific knowledge of the earthquake threat for operations (beneficiaries, staff, programs, systems), thus keeping it action-focused. As noted already, poor construction practices and non-implementation or lack of compliance with building codes are significant factors affecting earthquake risk in Bangladesh. Tackling these issues was beyond the scope of this particular project, and we emphasized earthquake preparedness and operational risk management rather than addressing the structural aspects of earthquake risk in order to keep the discussion focused on action. This is where the experience of the IRC in responding to disasters was particularly valuable. Third, the wider discussions during the course helped to ensure that the participants are able to make use of existing scientific information and integrate it with other types of knowledge (including community local knowledge). The group discussions provided a space where the participants were able to clarify anything that was unclear and where topics like earthquake prediction could be discussed.

Using Sargeant's observations from the process of developing and facilitating the workshop, we can reflect on the recommendations set out in Southgate et al. (2013) as follows:

Recommendation 1: Encourage science to demonstrate that it can inform policy and practice-It is possible to demonstrate what scientific knowledge informed the content and design of the training course and how it was implemented. Clear action points were identified by the participants during the training. However, no attempt was made to document the implementation of these once the training ended. Consequently, understanding how the training affected day-to-day decision making in the longer term within the different organizations that were represented is difficult to demonstrate and measure. While it could be argued that this may be beyond the role of science and the scientist, it is important to evaluate the impact of this kind of activity on decision making to improve future courses (e.g., Pearson, 2011).

Recommendation 2: Use a problem-solving approach to research that integrates all hazards and disciplines-Navigating the local context, working across disciplines and sectors, and
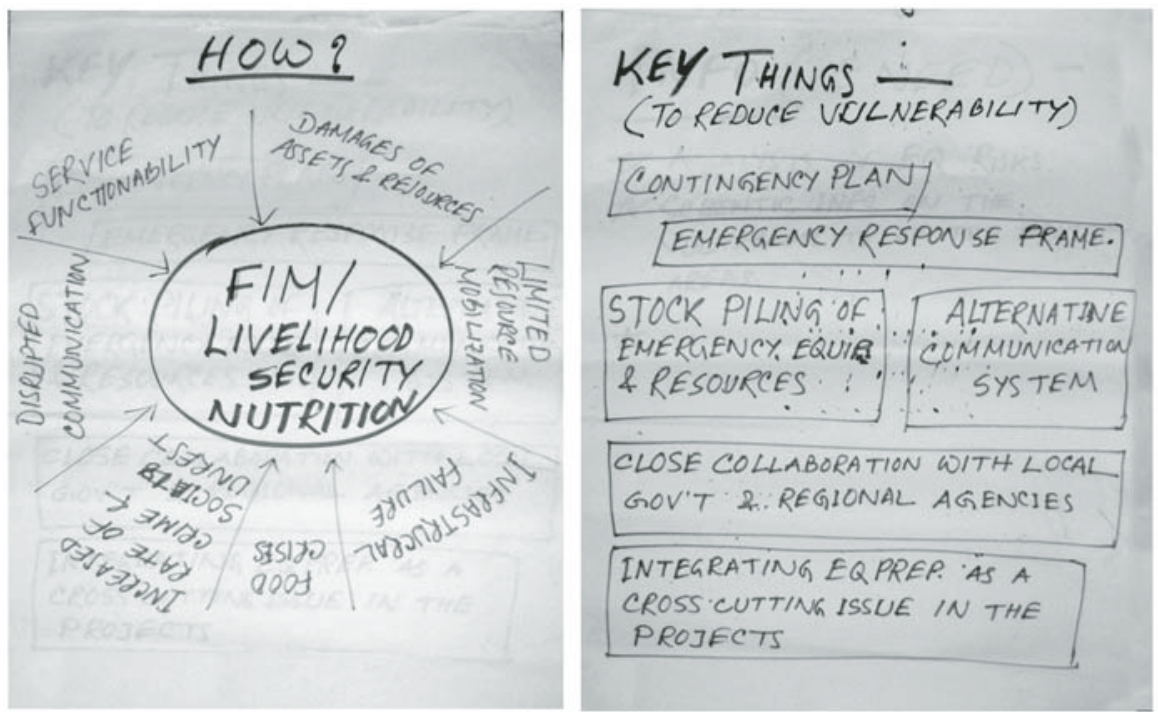

Figure 2. Some of the focus group outputs from a discussion of the potential impact of an earthquake on projects focusing on food, income, and markets (FIM) and livelihoods (left) and how the vulnerability of these activities could be reduced (right). 
building the necessary relationships with stakeholders to understand the problem (here, integrating earthquake information into organizational decision making in a complex setting), and working toward a developing an effective solution are vital aspects. This approach requires sustained engagement between the relevant stakeholders (in this case, Concern Worldwide and the IRC) in order to build the relationships, trust, and understanding required to work together effectively and in a way that has the potential for long-term impact. Development of sustained engagement is very resource intensive and can take a long time (years).

Recommendation 3: Promote knowledge into action, with greater emphasis on sharing and dissemination of informationSharing and disseminating scientific information and translating it into practical methods should be done with a good understanding of what scientific information is currently available and the organizational, infrastructural, or individual barriers that prevent this information from being accessed, shared, or acted on. Understanding the reasons these barriers exist and tackling them are important parts of the process. For example, some preparation (e.g., explaining fundamental earthquake concepts like magnitude) may be required before a nontechnical audience is able to make use of and act on more sophisticated scientific information (hazard and risk). In the case of this course, the mix of lectures and focus group discussions, and the opportunity to talk about these features did culminate in action plans.

Recommendation 4: Science should be key to the post-2015 HFA - The training course demonstrated that basic knowledge about earthquakes and their consequences can be very powerful. During the workshop, a number of participants said that they would talk to their families about what they had learned and develop earthquake preparedness plans at home. However, scientific evidence is only one element that will help a decision to be made or an action taken. The complexity of the decisionmaking process and the context in which it occurs (whether this is within an organization or outside) often make it difficult to measure exactly what impact science has had. One might ask whether decision makers should also provide evidence of what information has informed key decisions.

\section{Flooding and Wildfires in Boise, Idaho}

The geographic focus for the United States case study was the Boise River Basin, in southwest Idaho (Fig. 3), a complex and dynamic ecological and management environment. The basin includes $\sim 10,600 \mathrm{~km}^{2}$ of land subject to two significant and interconnected hazards-wildfires and flooding. The initial intent of the research on these hazards was to develop a better understanding of the stakeholders, their decision processes, their use of science in these processes, and their efforts to make or influence policy in the region. The subsequent objective was to compare these two hazard stakeholder networks in the Boise River Basin, characterized as "policy networks," or interorganizational groups of organizations, institutions, or stakeholders with similar inter- ests on specific issues or problems (see, for example, Marsh, 1998; Rhodes, 1997).

The Boise River is a tightly managed basin, with multiple dams and diversions, and it is regarded as a highly desirable amenity and ecosystem service provider for the region. Ecosystem services are those products and processes, such as water, food, and recreation, that link natural functions of the basin to the social and cultural values of the user (for example, Daily, 1997; Bolund and Hunhammar, 1999). Flowing from the mountains through urban and rural areas, subdivisions and agricultural land, and federal lands, the river is also a very polarizing construct in that diverse interests in regard to the river often do not share the same values, perceptions, and constituents.

Although actual regulatory and congressionally assigned decision and policy making for the Boise River Basin is in the hands of only a few agencies (U.S. Army Corps of Engineers and U.S. Bureau of Reclamation, for example), it is estimated that over 300 unique stakeholders, representing a diverse set of organizations, are engaged in using, supporting, and attempting to influence the decisions associated with the Boise River. Conversely, the wildfire policy network within the Boise River Basin is much smaller. Located primarily in the more densely populated Ada and Canyon Counties, the wildfire policy network has an estimated active interest population of $\sim 75$ organizations (as represented in annual workshops on regional wildfire issues).

The large number of local-level stakeholders in the Boise River Basin confirms the importance of local-level disaster response and policy networks in disaster risk reduction. Notably, the HFA implementation did not include local decision makers, governance structure, and context (UNISDR, 2005). Local Governments for Sustainability (ICLEI) independently recognized this gap in the HFA and advocated linking research and practice (Schreiber, 2014) and the use of science in support of local policy and decision making.

From the perspective of the use of science in disaster risk reduction, uncertainty regarding climate change impact is of primary interest here. In the wildfire policy network interactions and discussions, there was a general consensus among stakeholders about the high probability of wildfires in the region every season: Wildfire was essentially considered a certainty in spite of scientific uncertainty. Ongoing research by Lindquist on wildfires and risk perception of residents in the wild land-urban interface suggests that even though many newer residents have had no direct experience with these fires, they are well aware of the risk associated with where they chose to live. Residents have been educated through frequent television advertising and billboards warning about wildfires and posting current wildfire risk and fuel conditions in the area. Media attention to wildfires in the American West dominates the local news, keeping it foremost in the minds of viewers and residents.

The relative infrequency of river flooding in the Boise River Basin has had the opposite impact within the flood policy network, in that uncontrolled flooding was considered very unlikely. There is significant trust in the major agencies to manage future 
flooding events; however, these agencies may, in fact, be faced with more extreme situations in the future, in part as a result of increased floodplain development in the Boise River Basin as the urban area expands.

Related to the concept of uncertainty is the way in which the potential impact of climate change as a factor for policy making may vary (Berkhout, 2012). Climate change science (e.g., Intergovernmental Panel on Climate Change [IPCC] reports and national assessments such as those by Pachauri et al. [2014] and Melillo et al. [2014]) may be of significance to one group or stakeholder but relatively ignored by another. In the Boise River Basin policy networks, climate change has been widely accepted as having a probable impact on wildfires in the future, based on trends and climate science. The increased risk of wildfire relates to changes in precipitation, soil degradation, the introduction of nonnative and fire-prone grasses, and the overall ecosystem changes in the semiarid western United States. However, in regard to basin flooding, there has been little discussion of climate change as a factor, despite increased awareness of the issue and scientific warnings of higher probable risk. The difference in perception of increased risk may be a reflection of the more immediate and physical manifestation of wildfires and their link to climate change, as articulated in the media, as opposed to the more ephemeral link between a flood and the impact of climate change far upstream at the headwaters.

From this initial effort to identify and understand the Boise River Basin networks, and through Lindquist's participation in workshops and expert committees, we can consider the four key recommendations in Southgate et al. (2013):

Recommendation 1: Encourage science to demonstrate that it can inform policy and practice-Both hazard networks in the Boise River Basin involve the use of science and the engagement between science and policy, although the balance is different. Both cases rely heavily on scientific predictions, probability of risk and disaster, and aligning policy in response to the risk. In both cases, however, much of the time, the primary decision factors are the standard operating practices of the relevant agency or stakeholder with jurisdiction over the specifics of the decision context. While this situation is commonplace, and well understood, it calls into question many of the assumptions about the relevance and use of science in disaster risk reduction efforts when well-established protocols are already in place.

Recommendation 2: Use a problem-solving approach to research that integrates all hazards and disciplines-The wildfire policy arena is relatively inclusive of multiple disciplines, such as planning, policy sciences, and hydrology. A main method of

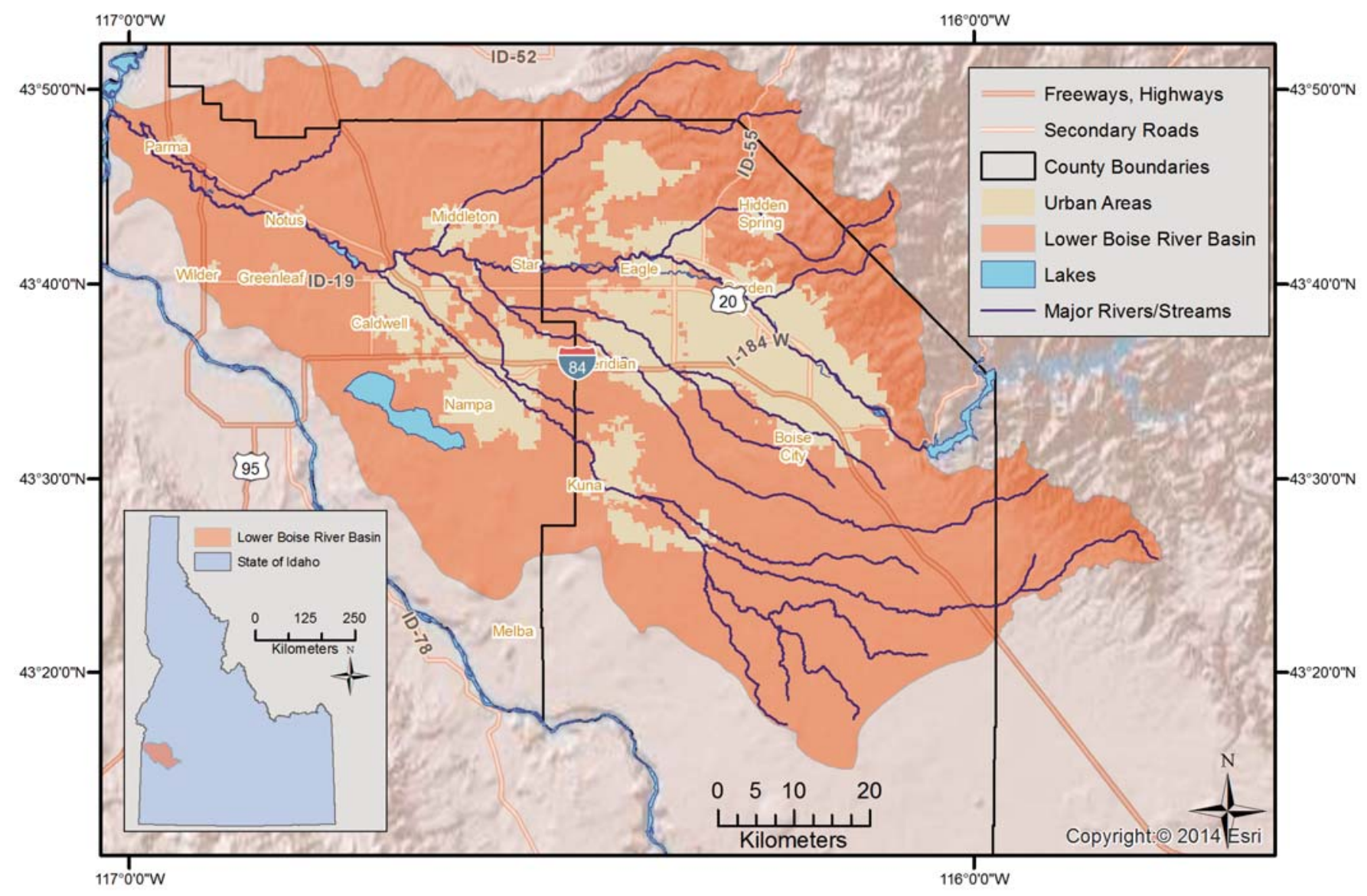

Figure 3. Boise River Basin region of southwestern Idaho. Image used with permission. 
addressing wildfire risk takes a rather individual and behavioral approach: It is up to the individual homeowner, for example, to create a resilient home, through applying fire-tolerant plantings and building materials. There are many individual and neighborhood programs designed to educate and encourage these behavioral changes. However, most problems associated with flood risk mitigation are solved by "hard" or infrastructure solutions, with an emphasis on engineering, and the built environment as a solution to flood risk, rather than policy or behavioral solutions. Many hazards exacerbate others (the increased probability of flooding after a wildfire has stripped vegetation off of hillsides, for example), and considering disaster risk reduction decision processes from a multiple-hazard perspective may be of more use to the public.

Recommendation 3: Promote knowledge into action, with greater emphasis on sharing and dissemination of information-In the case of the wildfire network, there is significant effort expended on education and knowledge transfer as a means to increase resilience to and mitigate against these events. On the other hand, the urban flooding problem is rarely mentioned or considered outside the domain of the few major stakeholders involved with flood risk management, such as the U.S. Army Corps of Engineers and the Idaho Bureau of Homeland Security. In the absence of flooding events in the basin, there is a community perception of being "safe," as well as trusting the agencies responsible for basin and water management. There is a stark difference in the assumption of responsibility across the two networks.

Recommendation 4: Science should be key to the post-2015 HFA-Science, and its use, as shown through the brief illustrations provided here, is but one factor in the larger information dissemination and advocacy efforts by stakeholders in both Boise River Basin networks. This observation confirms other studies showing the complexity and competition among information in the policy process: Decision makers are often bombarded with information (including science), and its use or lack of use is tempered by multiple factors, including trust and the limited capacity for assimilating information (see, for example, Keller, 2009; Kingdon, 2003; Jones and Baumgartner, 2005). In regard to the use of science in disaster risk reduction for the post-2015 HFA, understanding the dynamic reality of how decision makers accept and process information will be even more critical moving forward.

\section{BRINGING THE CASE STUDIES TOGETHER}

While case studies are commonly used in contextual policy and hazard research, one drawback is the reliance on a single case or policy domain (see, for example, Rochefort and Cobb 1994; also Rose, 2004). Given the multidisciplinary approach we take, considering the two cases together should better inform our response to the STAG call for "more effective interplay between science, policy and practice in support of DRR." Rose (2005) suggested the need for a framework within which to organize the cases in a systematic manner, and the recommendations in South- gate et al. (2013) act as a conceptual framework for bringing the two cases together. This highlights some common issues as well as differences.

\section{Recommendation 1: Encourage Science to Demonstrate that It Can Inform Policy and Practice}

Our collective findings suggest that there is significant activity in regard to decision making on which science has absolutely no impact, whether it is organizational change processes as in Bangladesh or agency-specific standard operating procedures in Idaho. This supports the assertion in much of the science-policy interface literature that science, in whatever form it takes, is "just one part of the complex decision making process," and that it competes with other information from many other sources (for a review, see, for example, Van Enst et al., 2014). If the scientific community better understood the decision-making context and the competition among information types and sources in a given case, we might better influence change for that case.

\section{Recommendation 2: Use a Problem-Solving Approach to Research that Integrates All Hazards and Disciplines}

While problem solving is critical to the use of science in guiding policy, the processes of defining the problem and designing solutions are inherently political and bound to specific organizational perspectives and culture. Further, while science can contribute to defining or highlighting the problem (trends in climate change or wildfires, or earthquake risk for examples), the problem itself may not be a scientific one. Our experiences illustrate the impacts of the lack of agency coordination and capacity, and uncertainty in identifying, accessing, and making use of the necessary scientific information within NGOs, for example. In regard to the importance of considering multiple hazards, the Idaho case identifies significant differences between perspectives of the flood and wildfire hazards. The linkages between these hazards are not currently being discussed by stakeholders, yet they should be on the agenda, considering the potential for compounding impacts of one hazard following another. The example in Bangladesh highlighted the great value of bringing together a diverse group of people with different skills, knowledge, experiences, and perspectives to understand the problem and identify possible solutions and ways forward.

\section{Recommendation 3: Promote Knowledge into Action}

There are identifiable efforts in each of our studied examples to promote the transition of knowledge to action. This is not, however, a clear-cut or linear process. How science converges, is shared, and goes through the system may not be a transparent or straightforward process. In fact, it may not happen at all because of a lack of communication and sharing, as is the case in Idaho across flood and wildfire hazard stakeholders, or because of mistrust among agencies or stakeholders. Science may also meet the system at different points in the disaster risk reduction process through different means, and this has implications for the type of information that is needed and how it is delivered (e.g., very 
sophisticated hazard and risk information, which might be needed for financial loss assessment at a high level or in the private sector, may not be appropriate for an audience that requires more basic information to raise community risk awareness). In light of these variations in the use and usefulness of knowledge, there is a need for more strategic science engagement. Our cases suggest that translating science into practical methods is a particular challenge because we need to first understand what science can influence under certain conditions. For example, structural versus nonstructural risk mitigation measures and alternatives are both supported by science, but we need to understand what people can or are willing to actually do, and what agencies and governance bodies can actually do, and how science fits into these constraints and opportunities.

\section{Recommendation 4: Science Should Be Key to the Post-2015 HFA}

In regard to this final recommendation, our collective observations suggest that science is a very important part of the process but that this recommendation as is it stated in Southgate et al. (2013) may perhaps overstate what science is capable of accomplishing or contributing. Science is only part of the larger decision-making process and under some conditions is not the most important factor. This recommendation also raises concern in regard to how we measure the impact of science in decision making for disaster risk reduction. Science is widely accepted as being routinely useful, but are we focusing too much on the product at the expense of understanding the decision-making process?

\section{CONCLUSIONS, REFLECTIONS, AND SUGGESTIONS FOR FUTURE RESEARCH}

We have applied a multidisciplinary and comparative approach to explore the implications of the recommendations on the use of science in disaster risk reduction that are set out in Southgate et al. (2013). Despite the differences in the two case studies in terms of hazard and geographic context, there are similarities in the way in which science is used in disaster risk reduction, and our observations broadly support these recommendations. However, the finer details of the science-policy interface that come into play need to be given careful consideration if science is to fully support the efforts of different stakeholders to reduce risk from multiple hazards.

Recent literature and discussions on the need for interdisciplinary research and perspectives on disaster risk reduction and on the use of science in decision making stress both the importance of scientific advice for disaster risk reduction and the complexity of the relationship among scientist, decision maker, and the public (for example, Gaillard and Mercer, 2012; Aspinall et al., 2003). These are fluid and dynamic relationships that will evolve over time and present both constraints and opportunities for bridging the science-policy interface. Our experiences stress the importance of consciously building relationships and trust, and understanding the context in which disaster risk reduction decisions are made. However, this cooperation needs to be integrated and sustained rather than confined to one-off studies.

In addition, it is not enough to collect and assess individual case studies to understand the role that science plays in disaster risk reduction. Although they do have great value, their collective findings may provide greater insight (Southgate et al., 2013). However, systematic and longitudinal assessment of the use of science in disaster risk reduction from an interdisciplinary perspective with consistent and sustained research design, application, and analysis is also needed. Research to better understand how science is used in disaster risk reduction should be a priority.

Two additional observations need to be raised here: First, the impact of our disciplinary perspectives on the process, and, second, our relative positions in the process. Our individual disciplinary perspectives influence our observations and focus, which we have recognized and attempted to navigate and manage in the collaborative process. Sargeant, for example, was in the position of a scientist engaged in knowledge-exchange activities that focused on increasing the impact of earthquake science on disaster risk reduction, while Lindquist was positioned more outside the process as a policy expert and contributor to the process. This is a case of experiential versus observational participation, as the authors have engaged directly in the processes but from different perspectives. As the collaboration evolves, these factors will help link theory with practice and enrich the discussion of what is beneficial both to the broader research community and to the local/individual decision maker, who may have very different needs and capacities.

Finally, we offer several observations and recommendations for a path forward, building on the experiences, diverse cases, and multidisciplinary collaboration presented here. While a collaborative, transdisciplinary, multiple-hazard approach to disaster risk reduction is widely advocated across agencies, academia, and by decision and policy makers, it is truly rare in practice, and even less so at the scale of addressing specific recommendations from the international disaster risk reduction community for more sciencepolicy interaction, such as those in Southgate et al. (2013). Our research has made an initial exploration into the use of science in disaster risk reduction decision making, yet our approach has limitations that need to be addressed moving forward. Specifically, the need to design an inter- or transdisciplinary collaboration from the outset in a systematic manner is clear to us, and we anticipate that the outcomes of subsequent systematic research will be strengthened significantly. We also recognize the importance of place-based interactions between scientists and the disaster risk reduction community, or actual engagement with disaster risk reduction stakeholders in situ. This direct connection will increase local trust in scientists and the scientific endeavor, in general, and provide important contextual insight informing both sides of the science-policy interface for the public good.

\section{ACKNOWLEDGMENTS}

The considerable input and guidance of staff from Concern Worldwide in Ireland and Bangladesh are gratefully acknowledged, 
as are the contributions of all the participants in the training. Particular thanks go to Willie McMartin from the International Rescue Corps for his input, advice, and enthusiasm in the development and facilitation of the training course. Thanks also go to Claire Greenwood for providing valuable feedback during the course development. Julian Bukits provided assistance with some of the figures. We also acknowledge the support and input from the Boise City Fire Department, Ada County Emergency Management, and the Idaho Bureau of Homeland Security. Thanks go to David Kerridge, Melanie Duncan, and Jen Schneider for useful feedback as we developed this paper. We would also like to thank Vahid Ahadnejad, Donald Bleiwas, and Donna Herring for their constructive and insightful reviews. This article is published with the permission of the Executive Director of the British Geological Survey (NERC).

\section{REFERENCES CITED}

Aspinall, W.P., Woo, G., Voight, B., and Baxter, P.J., 2003, Evidence-based volcanology: Application to eruption crises: Journal of Volcanology and Geothermal Research, v. 128, no. 1, p. 273-285, doi:10.1016/S0377 $-0273(03) 00260-9$.

Basher, R., 2013, Science and Technology for Disaster Risk Reduction: A Review of Application and Coordination Needs: http://www.preventionweb.net/ posthfa/documents/Science-and-Technology-for-Disaster-Risk-Reduction .pdf (accessed June 2015).

Berkhout, F., 2012, Adaptation to climate change by organizations: Wiley Interdisciplinary Reviews: Climate Change, v. 3, no. 1, p. 91-106.

Bilham, R., and England, P., 2001, Plateau "pop-up" in the great 1897 Assam earthquake: Nature, v. 410, p. 806-809, doi:10.1038/35071057.

Bolund, P., and Hunhammar, S., 1999, Ecosystem services in urban areas: Ecological Economics, v. 29, no. 2, p. 293-301, doi:10.1016/S0921-8009 (99)00013-0.

Carter, A., Armstrong, C., and Calkins, J., 2014, Mechanism for international science advice for disaster risk management: Discussion of a proposal to support the post-2015 Agenda: Planet@Risk, v. 2, no. 5, p. 308-311.

Cosgrave, J., 2008, Responding to Earthquakes 2008: Learning from Earthquake Relief and Recovery Operations: Prepared for ALNAP and the ProVention Consortium: http://www.alnap.org/resource/5239.aspx (accessed June 2015).

Daily, G., 1997, Nature's Services: Societal Dependence on Natural Ecosystems: Washington, D.C., Island Press, 392 p.

Gaillard, J.C., and Mercer, J., 2012, From knowledge to action: Bridging gaps in disaster risk reduction: Progress in Human Geography, v. 37, no. 1, p. 93-114, doi:10.1177/0309132512446717.

Henni, P.H.O., Fyfe, C.J., and Marrow, P.C., 1998, The BGS World Seismicity Database: British Geological Survey Technical Report WL/98/13, 9 p.

Javeline, D., and Shufeldt, G., 2014, Scientific opinion in policymaking: The case of climate change adaptation: Policy Sciences, v. 47, no. 2, p. 121139, doi:10.1007/s11077-013-9187-9.

Jones, B.D., and Baumgartner, F.R., 2005, The Politics of Attention: How Government Prioritizes Problems: Chicago, Illinois, University of Chicago Press, $316 \mathrm{p}$.

Keller, A.C., 2009, Science in Environmental Policy: The Politics of Objective Advice: Cambridge, Massachusetts, MIT Press, 278 p., doi:10.7551/ mitpress/9780262013123.001.0001.

Kingdon, J.W., 2003, Agendas, Alternatives, and Public Policies: New York, Longman Classics in Political Science, $240 \mathrm{p}$.

Marsh, D., 1998, Comparing Policy Networks: Philadelphia, Open University Press, $226 \mathrm{p}$.

Martin, S., and Szeliga, W., 2010, A catalog of felt intensity data for 570 earthquakes in India from 1636-2009: Bulletin of the Seismological Society of America, v. 100, p. 562-569, doi:10.1785/0120080328.
Melillo, J.M., Richmond, T.C., and Yohe, G.W., 2014, Climate Change Impacts in the United States: The Third National Climate Assessment: U.S. Global Change Research Program 841, http://nca2014.globalchange.gov/report (accessed June 2015).

Pachauri, R.K., Allen, M.R., Barros, V.R., Broome, J., Cramer, W., Christ, R., Church, J.A., Clarke, L., Dahe, Q., Dasgupta, P., and Dubash, N.K., 2014, Climate Change 2014: Synthesis Report: Contribution of Working Groups I, II and III to the Fifth Assessment Report of the Intergovernmental Panel on Climate Change: Geneva, Switzerland, Intergovernmental Panel on Climate Change, $151 \mathrm{p}$.

Pearson, J., 2011, Training and Beyond: Seeking Better Practices for Capacity Development: Organisation for Economic Co-operation and Development (OECD) Development Co-operation Working Paper 1, doi:10.1787/5kgf1nsnj8tf-en (last accessed December 2015).

Rhodes, R.A., 1997, Understanding governance: Policy Networks, Governance, Reflexivity and Accountability: Philadelphia, Open University Press, $235 \mathrm{p}$.

Rochefort, D.A., and Cobb, R.W., 1994, The Politics of Problem Definition: Shaping the Policy Agenda: Lawrence, Kansas, University Press of Kansas, $216 \mathrm{p}$.

Rose, R., 2005, Learning From Comparative Public Policy: A Practical Guide: London, Routledge, $160 \mathrm{p}$.

Schreiber, F., 2014, Looking ahead to the post-2015 framework for disaster risk reduction-Outcomes of the Resilient Cities 2014 Congress: Planet@ Risk, v. 2, no. 5, p. 318-323.

Southgate, R.J., Roth, C., Schneider, J., Shi, P., Onishi, T., Wenger, D., Amman, W., Ogallo, L., Beddington, J., and Murray, V., 2013, Using Science for Disaster Risk Reduction: http://www.preventionweb.net/files/32609 stagreport2013assembled.pdf (accessed June 2015).

Turnhout, E., Stuiver, M., Klostermann, J., Harms, B., and Leeuwis, C., 2013, New roles of science in society: Different repertoires of knowledge brokering: Science and Public Policy, scs114, http://spp.oxfordjournals.org/ content/early/2013/02/01/scipol.scs114.short (accessed June 2015).

UNISDR, 2005, Hyogo Framework for Action 2005-2015: Building the Resilience of Nations and Communities to Disasters: UNISDR A/ CONF.206/6, http://www.refworld.org/docid/42b98a704.html (accessed 29 October 2014).

UNISDR, 2006, NGOs and Disaster Risk Reduction: A Preliminary Review of Initiatives and Progress Made: http://www.unisdr.org/2008/partner-netw/ ngos/meeting 1-october-2006/NGOs_and_DRR_Background_Paper.pdf (accessed 16 June 2016).

UNISDR, 2009, Reducing Disaster Risks through Science: Issues and Actions, The Full Report of the ISDR Scientific and Technical Committee: http:// www.unisdr.org/we/inform/publications/11543 (accessed June 2015).

UNISDR, 2013, Bangladesh Tragedy Underlines How Deficient Building Codes Can Fuel Disasters: UNISDR Press Release 2013/11, http://www .unisdr.org/files/32598_2013no11.pdf (accessed June 2015).

Van Enst, W.I., Driessen, P.P., and Runhaar, H.A., 2014, Towards productive science-policy interfaces: A research agenda: Journal of Environmental Assessment Policy and Management, v. 16, no. 01, p. 1450007, doi:10.1142/S1464333214500070.

Van Schendel, W., 2010, A History of Bangladesh: New York, Cambridge University Press, $347 \mathrm{p}$.

Wang, Y., Bruce, J., Shyu, H., Sieh, K., Chiang, H.-W., Wang, C.-C., Aung, T., Lin, Y.N., Shen, C.-C., Min, S., Than, O., Lin, K.-K., and Thura Tun, S., 2013, Permanent upper plate deformation in western Myanmar during the great 1762 earthquake: Implications for neotectonic behavior of the northern Sunda megathrust: Journal of Geophysical Research-Solid Earth, v. 118, no. 3, p. 1277-1303, doi:10.1002/jgrb.50121.

World Bank, 2010, Natural Hazards, UnNatural Disasters: The Economics of Effective Prevention (Overview): https://openknowledge.worldbank.org/ handle/10986/2512; License: CC BY 3.0 IGO (accessed June 2015).

World Bank, 2013, Population, Total: http://data.worldbank.org/indicator/ SP.POP.TOTL (accessed October 2014).

ManusCript AcCePted by the Society 21 October 2015

Manuscript Published Online 7 March 2016 